\title{
Fewer Boundaries between Employers and Employees Emerge on The Coattails of Health Care Reform
}

\author{
Michelle Beckford*
}

Saint Peters University, Department of Nursing, 2641 John F. Kennedy Boulevard, Jersey City, NJ 07306

\begin{abstract}
The Affordable Care Act (ACA), legislated under the Obama administration, will be fully implemented by 2014. The premise of this health care reform is to make insurance coverage available to a majority of the nearly 50 million uninsured Americans. Cost containment is integral to the viability and longevity of such a significant endeavor. To date $85 \%$ of the U.S. population enjoys employer based health care benefits. As part of health care reform, the insured are being pushed to be more responsible consumers of health care services. The insured are also being asked to be better stewards of health behaviors. Under the premise of reform, employers are seizing the opportunity to mandate enrollment in newly established Accountable Care Organizations (ACOs). Thus there may be greater involvement of employing agencies into what was once considered private personal health information. When employers oversee and monitor the health behaviors of employees there becomes a potential conflict of interest, loss of individual autonomy, and discrimination becomes apparent. The end result could be a greater paternalistic role for the employer. There is a possibility of job loss and consequential lack of health insurance for those who are most in need.
\end{abstract}

Keywords: Autonomy, health, employer.

As the U.S. inches closer to 2014, the full - fledged inception of the Affordable Care Act (ACA) will undoubtedly emerge with features perhaps not fully anticipated. Americans are surely enticed by the premise of coverage for the large numbers of uninsured, and weary of the limitations on current health insurance. Still, the controversy surrounding health care reform indicates that many are not completely convinced that the current system should be abandoned. People are discontented by the increased bureaucracy, decreased autonomy and impersonalized medical attention received [1]. The President's philosophy of "if you like your coverage keep it", does not translate literally. With the rise of Accountable Care Organizations, comes the restructuring of health care delivery that has existed under previous models of health maintenance organizations. Thus a person's previous health insurance coverage may only exist in the context of larger employee accountability, responsibility and disclosure. In some situations, participation as defined by the employer is mandated.

While Americans have expressed dissatisfaction with the delivery of health care, $85 \%$ of citizens continue to enjoy employer -based coverage [2]. Many Americans receiving employer - based health insurance are insulated from the actual costs involved in health care delivery. In essence, the trajectory of health care reform will be a shift away from the current employer based system toward the individual consumer [3]. There is an imbalance in health care consumption

*Address correspondence to this author at the Saint Peters University, Department of Nursing, 2641 John F. Kennedy Boulevard, Jersey City, NJ 07306; Tel: 973-534-4779; E-mails: mbeckford@saintpeters.edu when consumers are shielded by third party reimbursement; moral hazard ensues. When people are accountable for their own consumerism they frequently skimp on preventative care. Another way of understanding moral hazard is that health care has become so expensive because it became so cheap [4]. The currently high number of uninsured Americans contributes to escalating health care costs because those that are uninsured do not seek primary health care and utilize more expensive routes of care, such as the emergency room, when they become ill. Recent studies indicate that about $33 \%$ of those without insurance had utilized the services of an emergency room or had stayed as an inpatient between the years of 2001 and 2005 in comparison to about 15\% of those with insurance [5]. Other studies show that it is not just the uninsured using emergency rooms as a point of entry for health care. Frequent users of the ER also tend to be those covered by Medicaid and/or Medicare. Many of the Medicaid and Medicare patients do not have a primary care physician. Low reimbursement rates and increased bureaucratic red tape dissuade some health care providers from treating Medicare and/or Medicaid recipients [2]. Also Medicaid does not require deductibles or co payments when a person presents to the emergency room [6]. Cost control and appropriate point of access to health care are not only desirable, but are necessary for overall utility. In a quest to manage the skyrocketing cost of health care benefits under the ACA, the shift is toward preventative care. Employers are seizing the opportunity to push the limits of what may once have been thought of as personal, confidential health information. For example, who imagined that in the context of being hired, potential employees would be required to disclose their weight? Even more controversial, the possibility of being fined for not putting forth such disclosure seems not just 
foreign but Draconian. Employees of CVS are facing this dilemma. CVS Caremark (CVS) announced that it would be asking employees receiving employer-sponsored health care coverage to reveal their height, weight, and body fat percentage to the company's insurance carrier as part of a wellness screening program to encourage workers to be more proactive in their health care and to bring down spiraling coverage costs [7]. The likelihood is that other large companies will follow suit, ultimately changing the boundaries between employer and employee. While health care reform has been largely thought to erode the current employer based system of health care insurance, what is actually arising may be a more autocratic role of employers in dictating wellness for their employees. Thus a larger role in a paternalistic sense, evidenced by an increased scope of what is considered appropriate elements of self -disclosure and consumer participation. Under the guise of creating a pool of healthier employees, comes the significant possibility for invasion of privacy, discrimination, stereotyping. While it is hard to argue against the cost benefits associated with well employees, these conditions of employment may serve to undermine employee experience, job qualifications, and aptitude for the position. Is there justice in society when a thinner employee, has a greater likelihood of being hired compared to a person who has the same qualifications but may weigh thirty pounds more? It seems that such policy will perpetuate the stigma associated with obesity and health disabilities. We allow persons on trial to plead the Fifth Amendment so as not to incriminate them, but we may not afford the same right to potential employees who wish to keep body size measures to themselves. What constitutes invasion of privacy? Can employers then require any additional information that could be relevant to health? This could open a Pandora's box regarding individual rights. In the context of a depressed economy, the employer with an employment opening clearly has the upper hand in coercing a potential employee into self - disclosing personal health information. Whereas previously employers were largely responsible for administering and financing health benefits, the ACA may facilitate a power structure shift in which the employer becomes directly responsible for the provision of services.

Another consideration will be the impact on health outcomes that arises out of such policies. It is difficult to mandate a person to change their health status with the notion of penalty, much as it is difficult to mandate psychotherapy for the person who is not motivated or so inclined. Whatever happened to individual autonomy? How much information is too much information for employers to have about their employees? It seems probable that conflicts of interest arise when employers are directly involved in monitoring the health care status of their employees. The logical progression would be for the employer to eliminate risky employees from their ranks. Inevitably this may lead to higher rates of unemployment and lack of health care insurance for those most at risk. Is this an inadvertent consequence of the ACA or another measure to sweep consumers into a public pool rather than a private sector for the provision of health insurance?

Hackensack University Medical Center has recently announced that it is launching its new accountable care organization. The ACO will enroll the medical center's employees in a new approach to health care delivery. The program is touted as a method to engage employees in their own wellness, to improve health, and control costs [8]. The stated goals are undeniably virtuous withstanding the potentially biased partnership. Thus the ACA is ushering in a new era of health care delivery, one fraught with potential ethical conflicts. The distinction between the patient role and the employee role becomes blurred. At the very least it minimizes the freedom to choose where to receive health care services. Is this an innovative strategy for involving consumers in their own wellness or is it a little too precarious to have your health care intimately tied to the same organization that is writing your paycheck? The evolving policies give new meaning to employer-based health insurance.

\section{REFERENCES}

[1] Cogan JF, Hubbard RG, Kessler DP. Healthy, Wealthy, \& Wise. Stanford: The Hoover Institution 2005.

[2] Emanuel EJ. Health care, Guaranteed. New York: Public Affairs 2008.

[3] Weisberg J. We are what we treat. Newsweek 2009; 27.

[4] Gratzer D. The Cure: How Capitalism Can Save American Health Care. 2006. heritage.org. Retrieved on 11 Nov. 2008: from: $<$ http://www.heritage.-org/research/lecture/the-cure-howcapitalism-can-save-american-health-care>

[5] Many Middle-Income Americans Lack Insurance; A Study: 40 Percent Without Coverage in 2005, Up From 28 Percent in 2001. MSNBC News. Retrieved from: <http://www.nbcnews.com/$\mathrm{id} / 12480260 / \mathrm{ns} /$ health-health_care/t/many-middle-incomeamericans-lack-insurance/\#.Ui48WL9LzUo>

[6] Zinser L, Hsieh P. Moral Health Care Vs. Universal Health Care. Winter 2007-2008. Obj Stand A J Cul Pol. Retrieved from: $<$ http://www.theobjectivestandard.-com/issues/2007-winter/moralvs-universal-health-care.asp>

[7] Rogers, K. Will More Companies Start Playing Employee Weight Game? 2013. Retrieved from: <http://www.foxbusiness.com/personal-finance/2013/03/21/cvs-health-care-mandate-employeesweight/\#ixzz2RfsSPaEs $\geq$

[8] Fitzgerald B. Hackensack UMC will enroll employees in its accountable care organization 2010. Retrieved from: http://www.njbiz.com/article/20110907/NJBIZ01/110909916. 